\title{
Protein Crystallization As a Process Step in a Novel Meso Oscillatory Flow Reactor: Study of Lysozyme Phase Behavior
}

\author{
Filipa Castro, ${ }^{*}{ }^{\dagger}+$ António Ferreira $^{\dagger}$ José A. Teixeira, $^{\dagger}$ and Fernando Rocha ${ }^{\dagger}$ \\ ${ }^{\dagger}$ LEPABE-Laboratory for Process Engineering, Environment, Biotechnology and Energy, Faculty of Engineering of the University of \\ Porto, Universiyt of Porto, Rua Roberto Frias, s/n, 4200-465 Porto, Portugal \\ ${ }^{\ddagger} \mathrm{CEB}$-Centre for Biological Engineering, University of Minho, Campus de Gualtar, 4710-057 Braga, Portugal
}

\begin{abstract}
In the present work, it is reported for the first time the study of the applicability of a novel meso oscillatory flow reactor (meso-OFR) for protein crystallization as a process step. Crystallization assays carried out in the designed device enabled to derive a two-dimensional lysozyme phase diagram (lysozyme concentration against sodium chloride concentration). Results evidence the formation of several types of crystals (different size and shape), with a strong influence of salt concentration on crystal shape. Results also show that

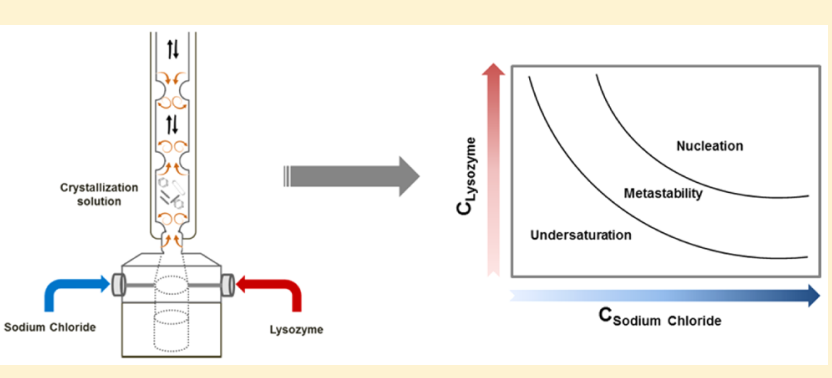
lysozyme remains active at the end of the experiments. Furthermore, it was possible to verify the reduction of the metastability zone when compared to lysozyme crystallization conducted under quiescent conditions. Induction times were also measured by online monitoring of the turbidity of the crystallization solution, obtained values being between 41 and $900 \mathrm{~min}$. Beyond providing improved understanding of protein phase behavior under oscillatory flow mixing, the results are very promising regarding the feasibility of the designed methodology for protein crystallization as a process step.
\end{abstract}

\section{INTRODUCTION}

Protein crystallization has been focused on the production of diffraction-quality single crystals for protein structure determination by crystallography. ${ }^{1-3}$ Research conducted during the last years has led to improved methodologies for the production of high-quality protein crystals allowing obtaining high-quality $\mathrm{X}$-ray diffraction patterns, and leading thus to information on structure biology. ${ }^{3}$ However, protein crystallization also offers many advantages as a means of protein purification at the industrial scale. Compared to conventional purification techniques, such as chromatography, crystallization is a cost-effective alternative since high-purity proteins can be obtained from a single-step operation. ${ }^{2,4-8}$ Further, protein crystals have a longer storage life and greater purity than the dissolved form, which opens up the number of potential applications for the pharmaceutical industry, from formulation and storage of proteins to drug delivery. $1,4,9$

Unlike protein structure determination, where single, large, stable, and well-diffracting crystals are required and usually obtained by slow-growing processes, rapid and quantitative crystallization is needed for large-scale protein purification processes. As most of the industrial processes, recovery yield, as well as purity must be high and the crystallization time low, so that growth kinetics should be fast (hours). ${ }^{2,4,10,11}$ Moreover, reagents must be inexpensive, compounds should be of pharmaceutical grade and proteins must not lose their potency after crystals are redissolved. ${ }^{1,11}$ In contrast to structural analysis, large single crystal shape is not as important, but crystals with a certain size, shape, and mechanical strength are desirable, so that they can be easily separated from their mother liquor, namely by filtration or centrifugation. ${ }^{1,2,10-12}$

Identification of crystallization conditions of a protein is still difficult, particularly for purification purposes where the crystallization step has to meet specific requirements. ${ }^{4,11,13}$ It requires knowledge about the thermodynamic properties of the protein solution, concentration of the protein, temperature and characteristics of the solvent (e.g., $\mathrm{pH}$, ionic strength, buffer concentration and identity, and any additives). ${ }^{3,14}$ The traditional method to study protein solubility, in response to different operating conditions, is to construct a phase diagram, commonly protein concentration against precipitant agent concentration. A phase diagram is divided by the solubility curve into two areas corresponding to undersaturated and supersaturated state of a protein solution. The supersaturated area comprises of the metastable, nucleation and precipitation zones. $^{3,10,11,13,14}$ In the nucleation and precipitation zones the protein is either crystalline or precipitated, whereas in the metastable zone the probability of nucleation occurrence is very low but already existing crystals could grow. ${ }^{3}$ However, complete phase diagrams for prediction of protein crystallization are rarely available and crystallization conditions are usually found by a trial-and-error approach. The few reports published include the work of Hekmat ${ }^{12}$ and Smejkal ${ }^{5}$ on the crystallization of lysozyme, the works of Smejkal ${ }^{9}$ and Hebel ${ }^{15}$

Received: February 17, 2016

Revised: April 15, 2016

Published: May 11, 2016 
both on the crystallization of therapeutic antibodies and more recently the study conducted by Huettmann ${ }^{11}$ on the crystallization of interferon gamma.

While protein crystallization is usually performed under quiescent conditions, protein crystallization as a process step requires a minimum of agitation. Otherwise crystals sink to the bottom, grow into each other and the crystal growth is diffusion limited leading to long process durations or low yields. ${ }^{9,16}$ Studies concerning the influence of the type and degree of agitation on protein crystallization can be found in the literature. A reduced nucleation time was observed in an unbaffled stirred vessel, ${ }^{17}$ in a wave shaker $^{18}$ and under oscillatory flow. ${ }^{16}$ Smejkal et al. ${ }^{5}$ observed a significantly faster onset of the crystallization of lysozyme and Fab-fragment of the therapeutic antibody Canakinumab in stirred vessels when compared to nonagitated systems. Besides, authors verified that further increase of the agitation rate resulted in the decrease of lysozyme crystallization onset. In contrast, a prolonged nucleation time was verified in a rotary shaker ${ }^{19}$ and under mechanical vibration. ${ }^{20}$ Vekilov and Rosenberger ${ }^{21}$ suggested that lysozyme growth cessation and deceleration were due to convection-enhanced supply of impurities to the interface. Shear forces were also related to limit the attachment of lysozyme growth units. ${ }^{22}$

Another key issue concerns the scalability of the process. ${ }^{1,11}$ Protein crystallization on process scale is usually performed in stirred tank crystallizers. Commonly suggested scale-up criteria such as minimum agitation rate to keep the crystals in suspension or impeller tip speed are not always successful and sometimes the scale-up criterion has to be based on experimental data. ${ }^{9,23}$ Moreover, large stirred tanks are usually characterized by low mixing efficiency that gives rise to excess local concentrations, ${ }^{4}$ and in its turn leads to spontaneous nucleation. Besides, shear stresses exerted by the impellers can lead to protein denaturation and damaged crystals. ${ }^{4,7}$ Another important concern is the fact that often limited amounts of protein are available, making difficult the implementation of experiments on a large scale.

So far, only a few reports have been published on protein crystallization as a process step. The most prominent example is the industrial implementation of the crystallization process of insulin. ${ }^{23}$ Other examples include studies on the crystallization of lysozyme, ${ }^{5,12,15,24-26}$ ovalbumin, ${ }^{17}$ L-methionine $\gamma$-lyase, ${ }^{27}$ fungal lipases, ${ }^{10,28}$ and urate oxidase. ${ }^{29}$ Studies have also been reported on more complex proteins like monoclonal antibodies, ${ }^{9,11,30}$ more difficult to crystallize due to their large size and structural flexibility. ${ }^{15}$ More recently, Neugebauer and Kinast ${ }^{7}$ reported the development of a tubular-plug flow crystallizer for the continuous lysozyme crystallization. Although the studies published show the feasibility of protein crystallization as a means of purification, further work is required to establish the latter as an alternative to the existing downstream processing techniques. A limited number of works were performed under well-defined and scalable operating conditions. ${ }^{7}$ In addition, some of the reports lack information about protein phase behavior, crystallization kinetics and yield, ${ }^{31}$ and flow conditions. $^{29}$ Furthermore, rather long process durations or low yields were observed in most cases. $9,16,29-31$

To overcome some of the gaps observed in common crystallizers, a novel meso oscillatory flow reactor (meso-OFR) was developed by members of the present research team. ${ }^{32}$ The device is operated under oscillatory flow mixing that has been proved to result into significant enhancement in processes such as mass transfer and particle mixing, ${ }^{33,34}$ particularly relevant for crystallization processes. Indeed, significant enhancement in crystal characteristics and reduction of operation time have been reported for the crystallization of hydroxyapatite. ${ }^{35,36}$ In addition, the reactor can be easily scaled up by the addition in series of other identical meso-OFR unities. In this context, the present work aims to study, for the first time, the applicability of the meso-OFR on protein crystallization for purification purposes. Lysozyme was used as a protein crystallization model. Like any industrial process it is intended to obtain maximum yield and purification, and to achieve this rapidly. Control of crystal size is as well important. Optimization with respect to all these criteria has to be based on a fundamental understanding of the process, that is, knowledge of the phase diagram and kinetics. For this, different experimental conditions were screened by varying protein and precipitating agent concentration in order to derive a sufficiently quantitative crystallization phase diagram of the protein under study. Induction times were measured by online monitoring of the turbidity of the crystallization solution. The obtained crystals were characterized by optical microscopy and their activity was measured. Additionally, crystal yield was estimated.

\section{MATERIALS AND METHODS}

Protein and Chemicals. Chicken egg-white lysozyme was purchased from Sigma-Aldrich (Fluka-62971, Germany, lot no. $\mathrm{BCBJ} 2814 \mathrm{~V}$ ) and was used without further purification. One stock solution of $0.2 \mathrm{M}$ sodium acetate buffer at $\mathrm{pH} 4.7$ was prepared using sodium acetate trihydrate from Sigma-Aldrich (99,5\%, Germany) and glacial acetic acid from Merck (100\%, Germany) to adjust the $\mathrm{pH}$. Sodium chloride was obtained from Panreac AppliChem (99,5\%, Germany). Several lysozyme $\left(5-50 \mathrm{mg} \cdot \mathrm{mL}^{-1}\right)$ and sodium chloride $(2.5-6 \%(\mathrm{w} / \mathrm{v}))$ solutions were prepared in the sodium acetate buffer solution, $\mathrm{pH}$ of the sodium chloride solution being posteriorly adjusted with a $1 \mathrm{M}$ hydroxide sodium (Pronolab, Portugal) solution. All the solutions were prepared in ultrapure water (Milli $Q$ water, resistivity of $18.2 \mathrm{M} \Omega \cdot \mathrm{cm}^{-1}$ at $25{ }^{\circ} \mathrm{C}$ ) and filtered through a $0.2 \mu \mathrm{m}$ cutoff membrane (Sigma-Aldrich, Whatman, Germany). Lysozyme concentrations were measured by UV spectroscopy (ScanSpec UVvis, Sarspec, Portugal) at $280 \mathrm{~nm}$ using a known extinction coefficient $\left(2.5 \mathrm{~L} \cdot \mathrm{g}^{-1} \cdot \mathrm{cm}^{-1}\right)$. $^{9}$

Experimental Installation. Lysozyme crystallization trials were carried out in the experimental setup represented in Figure 1. It involves the meso-OFR placed vertically, a mixing chamber and a measuring cell connected to a spectrometer for turbidity measurement. The device consists of a $35 \mathrm{~cm}$ long and $3 \mathrm{~mm}$ internal diameter glass jacketed tube provided with smooth periodic constrictions (SPC) and has an approximate volume of $4 \mathrm{~mL}$ (Figure 1). The crystallization solution was oscillated using a piston moved by a stirring motor (CAT R100C, United States of America). The oscillating device was custombuilt. The reactor is operated under oscillatory flow mixing, controlled by the oscillation frequency $(f)$ and amplitude $\left(x_{0}\right)$ that were fixed at $1.83 \mathrm{~Hz}$ and $4 \mathrm{~mm}$, respectively. The value of the amplitude corresponds to the center-to-peak amplitude, and the measurements were performed in the tube without constrictions. Reactants were fed into the setup by means of a syringe pump (NE-4000, New Era, United States of America). Reactants were tempered and temperature inside the meso-OFR was regulated by a thermostatic bath (Huber, Ministat 125 , Germany) maintained at $20^{\circ} \mathrm{C}$.

Determination of Phase Diagram. Batch crystallization experiments with different lysozyme and sodium chloride concentrations were carried out at $\mathrm{pH} 4.7$ and $20^{\circ} \mathrm{C}$. As the conventional microbatch methodology, the solution is undersaturated, saturated or supersaturated at the beginning of each experiment. This allows a more accurate description of phase states with known operating conditions. ${ }^{3,14}$ Experiments were started by the simultaneous injection in the experimental setup of equal volumes of both lysozyme and 


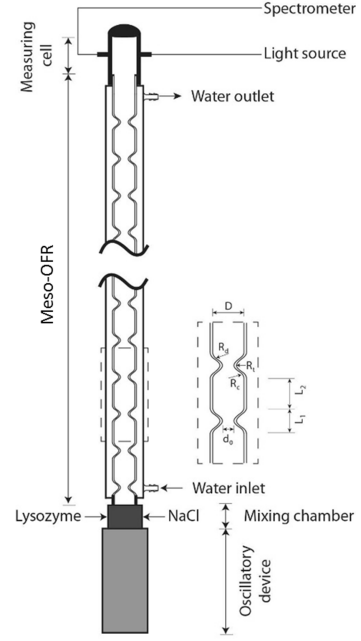

Figure 1. Schematic representation of the experimental setup for lysozyme crystallization experiments in the meso-OFR: D, internal tube diameter; $d_{\mathrm{o}}$, internal diameter in the constrictions; $L_{1}$, convergent-divergent section length; $L_{2}$, straight section length; $R_{c}$ radius of the curvature of the sidewall of the convergent section; and $R_{\mathrm{d}}$ radius of the curvature of the sidewall of the divergent section.

sodium chloride solutions. After $24 \mathrm{~h}$ of incubation, samples were investigated for crystals, precipitates or other structures by optical microscopy (Standard 20, Zeiss, Germany). The supernatant was filtered and diluted with ultrapure water for lysozyme concentration determination by UV absorbance $(\lambda=280 \mathrm{~nm})$. This procedure was carried out at least three times for each initial supersaturation $\left(S_{\mathrm{i}}=\frac{C_{\text {lysozyme initial }}}{\text { solubility }_{\text {lysozyme }}}\right)$. Then, a phase diagram was assembled (Figure 2).

Induction Time. Induction time $\left(t_{\text {ind }}\right)$ is known as the period between the establishment of supersaturation and the detection of a new phase. ${ }^{37,38}$ Increase of the crystals number in solution can be detected by measuring the turbidity of the crystallization solution, once the formation of a crystal suspension is expected to decrease light transmission. $t_{\text {ind }}$ can thus be determined by using the change in the transmission of light. In this way, online measurement of the turbidity of the crystallization solution was carried out with a spectrometer (ScanSpec UV-vis, Sarspec, Portugal) at $400 \mathrm{~nm}$ to monitor the crystallization process

$$
\tau=\frac{2.303}{d} \times A
$$

where $\tau=$ turbidity, $d=$ scattering path length (path length of the measuring cell being $0.4 \mathrm{~cm}$ ), and $A=$ absorbance.
Absorbance measurements of the crystallization solution allowed to build the turbidity profile curves, using eq 1 , for each experimental condition studied. Figure 3 shows a typical turbidity profile curve.

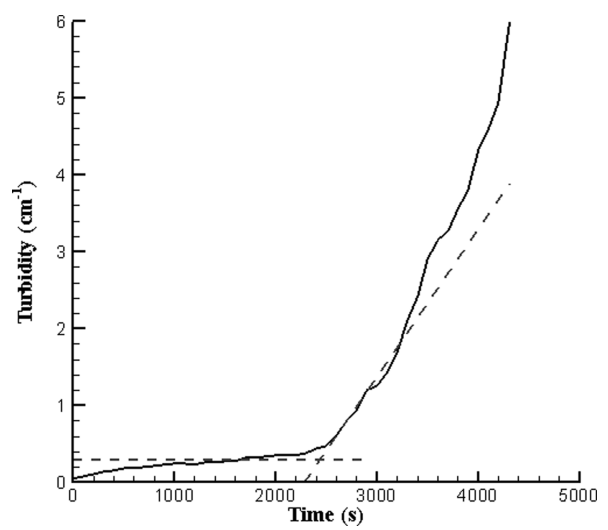

Figure 3. Typical turbidity profile obtained during lysozyme crystallization experiments (lysozyme $30 \mathrm{mg} \cdot \mathrm{mL}^{-1}, \mathrm{NaCl} 4 \%(\mathrm{w} / \mathrm{v}$ ), $\mathrm{pH} 4.7$, and $T=20^{\circ} \mathrm{C}$ and under agitation conditions of $f=1.83 \mathrm{~Hz}$ and $x_{0}=4 \mathrm{~mm}$ ).

During the time that precedes the formation of stable nuclei, turbidity is almost constant, while nucleation and growth of lysozyme crystals resulted in an abrupt increase in the turbidity. In this way, $t_{\text {ind }}$ was derived by the intersect value, on the axis time, of the tangent to the first rapid increase in the turbidity profile curve as illustrated in Figure 3.

Lysozyme Activity. Enzymatic activity of the lysozyme crystals obtained was determined by spectrophotometry and compared to the enzymatic activity of the initial lysozyme solution. The rate of lysis of Micrococcus lysodeikticus was determined, one unit being equal to a decrease in optical density (OD) of 0.001 per minute at $450 \mathrm{~nm}$ at $\mathrm{pH}$ 6.25 and $25{ }^{\circ} \mathrm{C}$.

\section{RESULTS AND DISCUSSION}

Lysozyme Phase Behavior. Batch crystallization experiments carried out in the meso-OFR enabled to derive lysozyme phase behavior under oscillatory flow mixing at $20{ }^{\circ} \mathrm{C}$ and $\mathrm{pH}$ 4.7 (Figure 4). The solubility ${ }^{39,40}$ and the metastability ${ }^{41}$ curves were drawn based on the data available in the literature at quiescent conditions. Clear solutions above the solubility curve were indicative of the metastable region, once in spite of being supersaturated these solutions were not able to produce crystals. As expected, increasing concentrations of both lysozyme and sodium chloride above the metastability curve
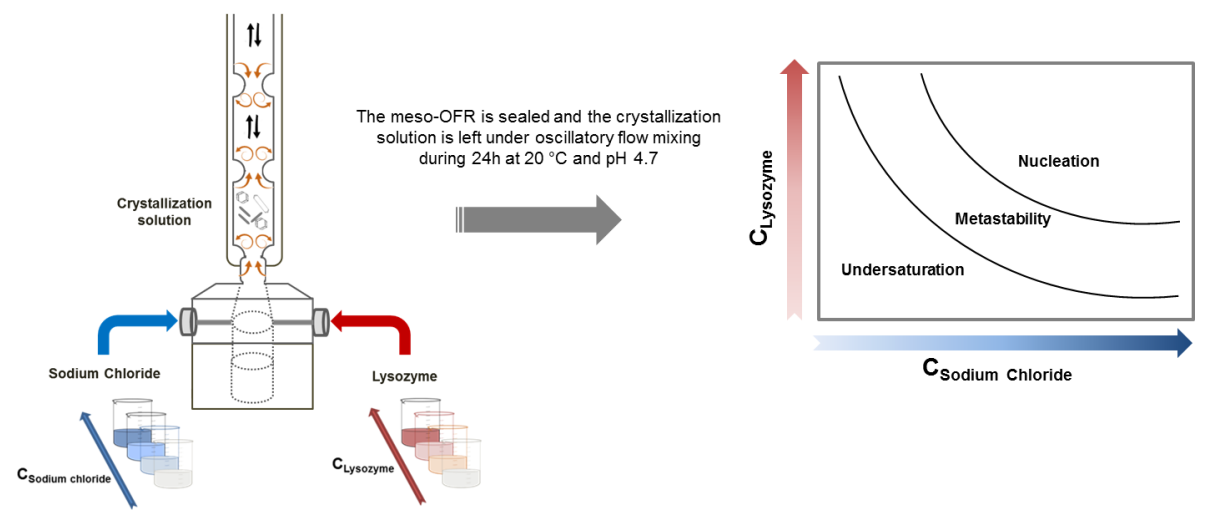

Figure 2. Schematic representation of the procedure employed for the generation of lysozyme phase diagram in the meso-OFR at $20{ }^{\circ} \mathrm{C}$ and $\mathrm{pH} 4.7$ and under agitation conditions of $f=1.83 \mathrm{~Hz}$ and $x_{0}=4 \mathrm{~mm}$. 


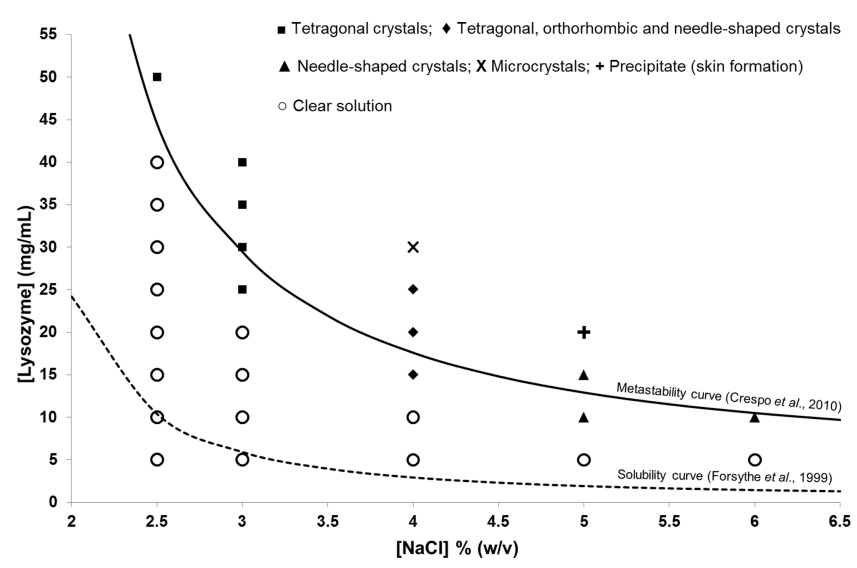

Figure 4. Lysozyme phase behavior in the meso-OFR at $\mathrm{pH} 4.7$ and $20{ }^{\circ} \mathrm{C}$ under agitation conditions of $f=1.83 \mathrm{~Hz}$ and $x_{0}=4 \mathrm{~mm}$.

led to crystallization and further increase to simultaneous crystallization and precipitation. Several types of crystals were observed, from tetragonal, orthorhombic and needle-shaped crystals to microcrystals and precipitate, depending on both reactants concentration but mostly on salt concentration (Figure 5). For sodium chloride concentrations below and equal to $3 \%(\mathrm{w} / \mathrm{v})$, essentially tetragonal crystals were observed. One can also verify that crystals with different sizes (about 5 to $15 \mu \mathrm{m}$ ) and aggregated crystals were obtained. For sodium chloride concentration of $4 \%(\mathrm{w} / \mathrm{v})$ and lysozyme concentration between 15 and $25 \mathrm{mg} \cdot \mathrm{mL}^{-1}$, samples were constituted by well-defined tetragonal and orthorhombic crystals with typical size around $10 \mu \mathrm{m}$ and needle-shaped crystals. Images also demonstrate the generation of aggregated microcrystals (with typical size about $3 \mu \mathrm{m}$ ) for higher lysozyme concentration $\left(30 \mathrm{mg} \cdot \mathrm{mL}^{-1}\right)$. For high concentrations of sodium chloride $(\geq 5 \%(\mathrm{w} / \mathrm{v}))$ and low concentration of lysozyme (10 to $15 \mathrm{mg} \cdot \mathrm{mL}^{-1}$ ) mainly needles with regular size and shape were formed, while increasing lysozyme concentration led to precipitation.

As known, crystallization of a protein involves reduction of the solubility of the protein, namely by the addition of precipitant agents. ${ }^{3}$ In the case of sodium chloride, the solvation layer around protein molecules is reduced, giving thus rise to solubility decrease. In this way, a direct relationship was verified between salt concentration and the appearance of lysozyme crystals. Results obtained also demonstrated a strong influence of salt concentration on the shape of lysozyme crystals. Under quiescent conditions, experimental conditions studied should only lead to the formation of tetragonal lysozyme crystals. ${ }^{39-41}$ However, for concentrations of sodium chloride equal and superior to $4 \%(\mathrm{w} / \mathrm{v})$ samples contain needle-shaped crystals. Bhamidi et al. ${ }^{42}$ suggested that needles were an unstable polymorph of lysozyme that slowly would convert to the tetragonal form. However, observations done on the collect suspensions kept during several months did not prove this hypothesis for all the cases.

In the present work lysozyme crystals are subjected to fluid shear forces induced by oscillatory flow mixing and solid-liquid interfaces. Lysozyme crystals collide with parts of the glass walls of the meso-OFR and with each other. In this way, crystalline fragments could be created by attrition leading to secondary nucleation that gives rise to excess nucleation and suppresses growth, and in its turn lead to small size crystals. ${ }^{43}$ Indeed, protein crystals are generally more fragile than crystals of inorganic and small organic molecules because of their high solvent content, ${ }^{44}$ so that they are highly likely to fracture during collision with each other or the crystallization equipment. Experimental results suggest the occurrence of a strong nucleation, since most of the experimental conditions studied led to the formation of a high number of small crystals and crystals with different sizes (Figure 5).

As shown in Figure 5, some aggregation could be observed. In what concerns protein crystals aggregation, literature reports many factors that can induce particle aggregation. Kusters et $\mathrm{al}^{45}$ suggested that aggregation for lysozyme crystals with a diameter in the range of $1-100 \mu \mathrm{m}$ is mainly induced by shear forces according to its Kolmogorov microscale. Other studies ${ }^{46}$ demonstrated that shear alone do not cause aggregation although prolonged exposure resulted in some minor reversible aggregation. In the present work, besides the fact that the lysozyme crystals have an average size in the order of $10 \mu \mathrm{m}$ (see Table 2), they are also subjected to shear stress, which may explain their aggregation.

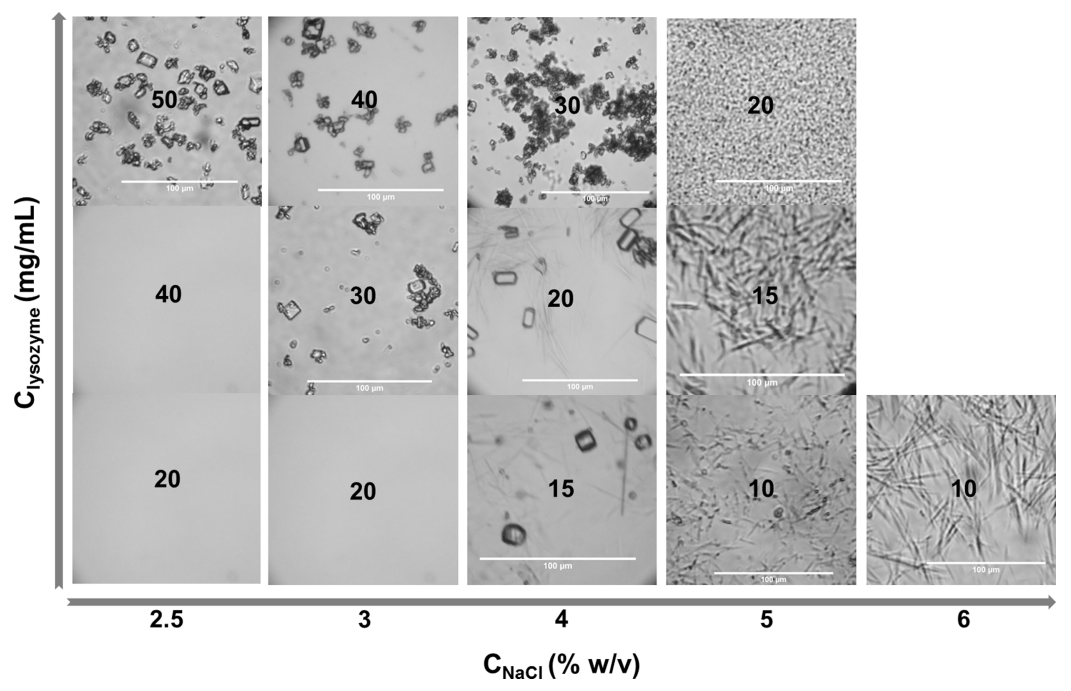

Figure 5. Lysozyme crystals obtained in the meso-OFR at $\mathrm{pH} 4.7$ and $20{ }^{\circ} \mathrm{C}$ under agitation conditions of $f=1.83 \mathrm{~Hz}$ and $x_{0}=4 \mathrm{~mm}$. Lysozyme concentrations used are mentioned in each picture. 


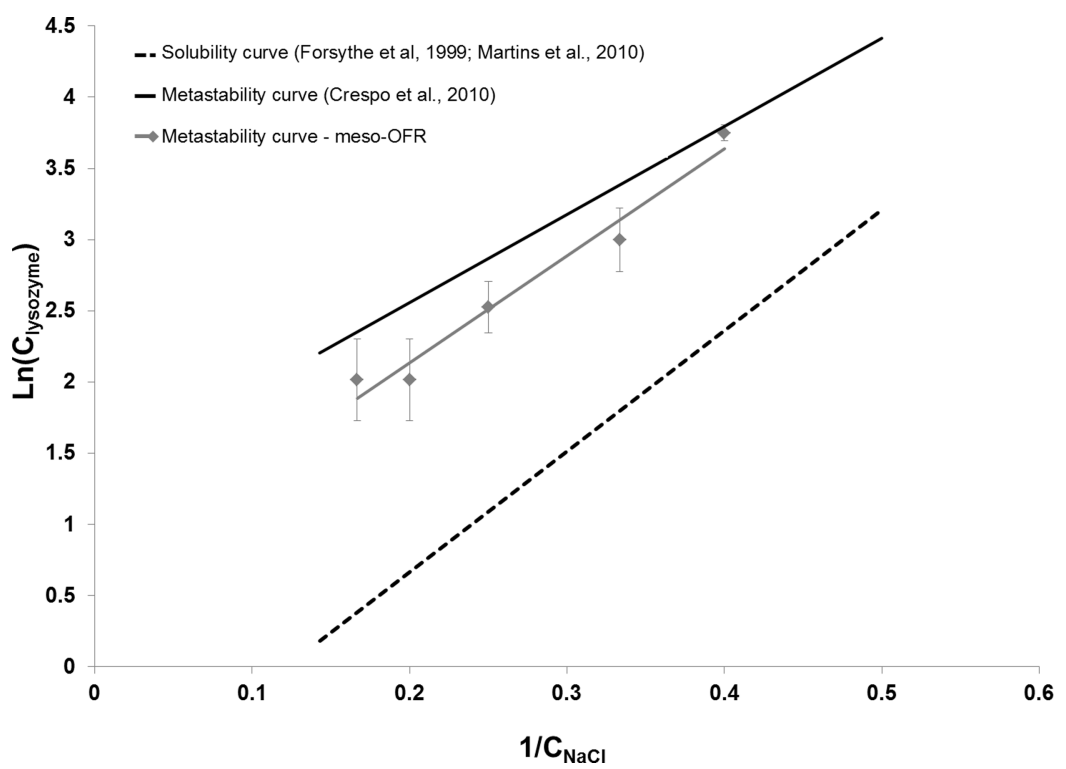

Figure 6. Linearized metastability curve for lysozyme crystallization carried out in the meso-OFR at $20{ }^{\circ} \mathrm{C}$ and $\mathrm{pH} 4.7$ and under agitation conditions of $f=1.83 \mathrm{~Hz}$ and $x_{0}=4 \mathrm{~mm}$. Solubility and metastability curves were obtained by curve fitting from data reported in the literature. ${ }^{39-41}$

Lysozyme Activity. Regarding the activity of the crystals collected, the results revealed that the protein collected is still active, since most of the samples exhibited at least $80 \%$ of activity when compared to the initial lysozyme solution.

It is commonly believed that denaturation is a prerequisite for aggregation, once small perturbations in protein structure may expose hydrophobic surfaces, causing self-interactions and consequential aggregation. ${ }^{46}$ According to the literature, ${ }^{47}$ long exposure time at solid-liquid interfaces ${ }^{48}$ and a moving gasliquid interface $e^{46,49-52}$ can cause damage to proteins. It has also been reported that this phenomenon is mainly due to the hydrophobic character of such interfaces. ${ }^{46}$ In the meso-OFR, lysozyme crystals are subjected to fluid shear forces and solidliquid interfaces. Furthermore, they are exposed to air-liquid interfaces, although there have been attempts to minimize them, once reactants were carefully injected in the system to avoid bubbles and the reactor was almost completely full. Given the little loss of activity, the aggregation observed may be mainly explained by exposure to shear stress as already suggested above.

Metastability Curve Determination. On the basis of lysozyme phase behavior (Figure 4), it was possible to determine the metastability curve based on the minimum sodium chloride concentration needed for nucleation at different lysozyme concentrations. Given the uncertainty associated with the experimental results and the stochastic nature of nucleation, a potential range for the metastability curve was represented (error bars). These results, as well as the solubility and metastability curves reported in the literature for microbatch experiments ${ }^{39,40}$ were linearized (see Figure 6) according to Martins et al. $^{40}$ equation

$$
C_{\text {lysozyme }}=A \exp \left(\frac{B}{C_{\mathrm{NaCl}}}\right)
$$

where $C_{\text {lysozyme }}$ is the lysozyme concentration in milligrams per milliliter, and $C_{\mathrm{NaCl}}$ is the concentration of sodium chloride in percentage units $(\mathrm{w} / \mathrm{v})$. The values of the constants $\mathrm{A}$ and $\mathrm{B}$ that best fit the experimental results are given in Table 1 .
Table 1. Values of $A$ and $B$ Constants from the Linearization of Both Experimental Metastability and Theoretical Solubility and Metastability Curves of Lysozyme at $20^{\circ} \mathrm{C}$ and $\mathrm{pH} 4.7$

\begin{tabular}{lccc}
\multicolumn{1}{c}{ linearized curve } & $A$ & $B$ & $r^{2}$ \\
solubility $^{39,40}$ & 0.354 & 8.45 & 0.973 \\
metastability $^{41}$ & 3.744 & 6.19 & 0.983 \\
metastability-meso-OFR $^{2}$ & 1.887 & 7.52 & 0.970 \\
\hline
\end{tabular}

According to Figure 6 and Table 1, metastability data can be described by the exponential relationship proposed by Martins et al., ${ }^{40}$ used for the description of lysozyme solubility curve with sodium chloride as the precipitant agent.

Reduction of the Metastability Zone. From the experimental and literature results (Figures 4 and 6), it was possible to illustrate the undersaturation, metastable, nucleation and precipitation zone (Figure 7), hence giving information about the relevant range of sodium chloride and protein concentration for lysozyme crystallization in the meso-OFR at $20{ }^{\circ} \mathrm{C}$ and $\mathrm{pH} 4.7$.

Graphical representation of the experimental metastability curve and both theoretical solubility and metastability curves clearly illustrates the reduction of the metastability zone when performing lysozyme crystallization under oscillatory flow mixing (Figure 7). For instance, for a lysozyme concentration of $15 \mathrm{mg} \cdot \mathrm{mL}^{-1}$, crystals were observed at $S_{\mathrm{i}}=5.4$ with oscillatory flow mixing, while under quiescent conditions appearance of crystals is only expected for $S_{i}$ values superior or equal to 6.3 (metastability data). Under agitation, collision between protein molecules is increased, increasing thus nucleation probability. As a result, metastability region is reduced leading to the occurrence of nucleation at lower supersaturation levels. Therefore, crystallization conditions that normally do not produce crystals may become successful using oscillatory flow mixing. This could be particularly interesting for proteins with a limited range of crystallization conditions, since the probability of crystals appearance can be increased under oscillatory flow mixing. 


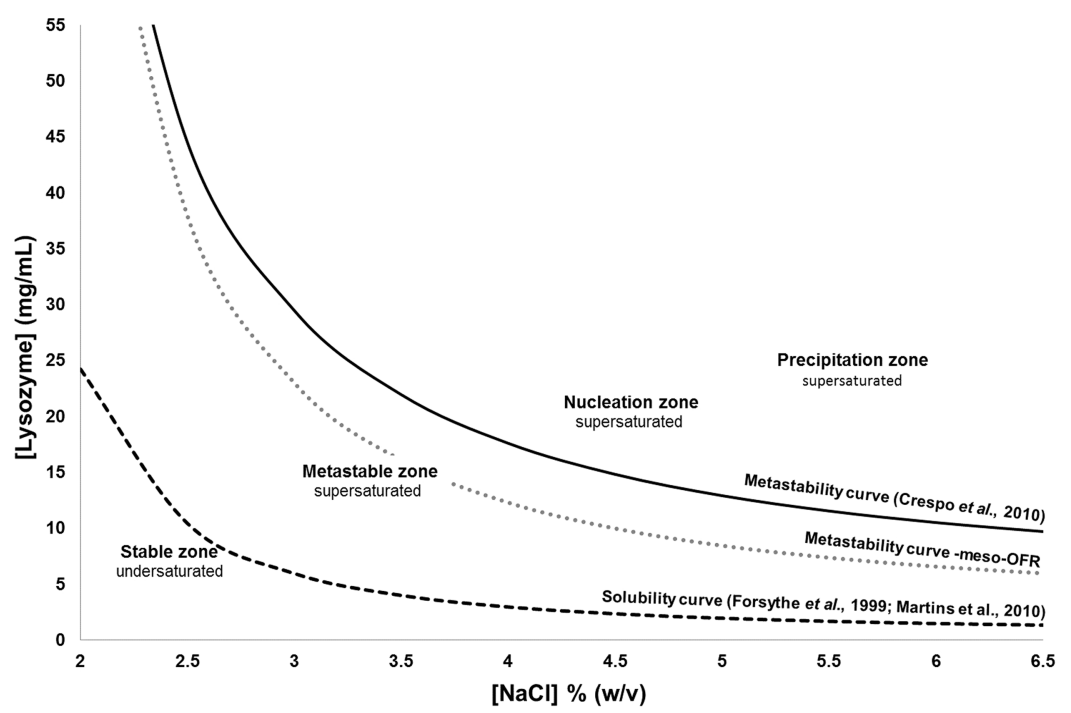

Figure 7. Lysozyme phase diagram in the meso-OFR at $\mathrm{pH} 4.7$ and $20{ }^{\circ} \mathrm{C}$ under agitation conditions of $f=1.83 \mathrm{~Hz}$ and $x_{0}=4 \mathrm{~mm}$.

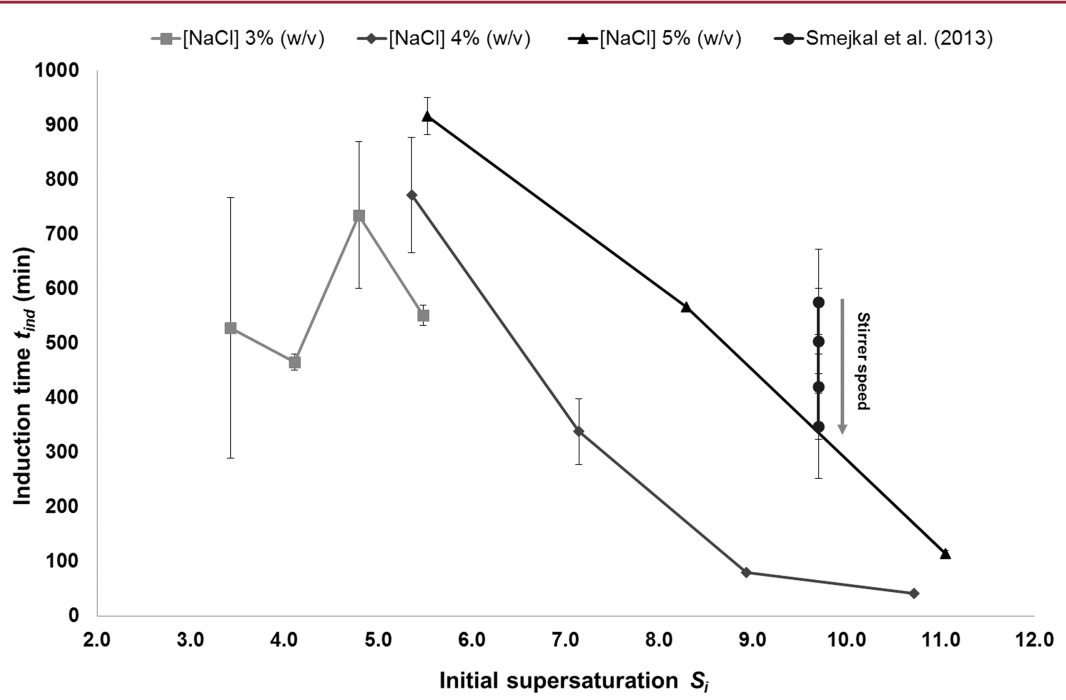

Figure 8. Induction time $t_{\mathrm{ind}}$ as a function of the initial supersaturation $S_{\mathrm{i}}$ for different sodium chloride concentrations: $3 \%(\mathrm{w} / \mathrm{v}), 4 \%$ (w/v), and 5\% $(\mathrm{w} / \mathrm{v})$. The error bars are standard deviations from at least three independent experiments. Smejkal et al. ${ }^{5}$ data was obtained in a stirred tank reactor of $6 \mathrm{~mL}$ for different stirrer speeds from 200 to $400 \mathrm{rpm}$ with sodium chloride concentration of $4 \%(\mathrm{w} / \mathrm{v}$ ) and lysozyme concentration of $50 \mathrm{mg}$. $\mathrm{mL}^{-1}$.

Induction Time. Measured induction time, $t_{\text {ind }}$, was plotted as a function of the initial supersaturation, $S_{\mathrm{i}}$, for the experimental conditions studied (Figure 8).

Nucleation is time-critical during protein crystallization processes as it determines the onset of crystallization. Further, nucleation controls crystal product quality aspects such as the kind of solid state and crystal size distribution. ${ }^{37}$ In this study, crystallization onset was evaluated through $t_{\text {ind }}$ measurement. According to Figure 8, typical values for $t_{\text {ind }}$ are between 41 and 900 min depending on the initial supersaturation $S_{\mathrm{i}}$. It is also important to refer that tetragonal crystals were essentially obtained at low $S_{\mathrm{i}}$, that is, at large $t_{\text {ind }}$ while needles and precipitates were preferentially formed at high $S_{i}$, that is, at short $t_{\text {ind }}$. One can also verify that for sodium chloride concentrations of $4 \%$ and $5 \%(\mathrm{w} / \mathrm{v}), t_{\text {ind }}$ decreases as $S_{\mathrm{i}}$ increases, while no direct relationship between $S_{\mathrm{i}}$ and $t_{\text {ind }}$ was evidenced for a sodium chloride concentration of $3 \%(w / v)$. It is important to mention that the value of the induction time depends strongly on the methodology employed to detect the formation of new nuclei. In this study, measurement of the induction time is based on the detection of an abrupt increase in the turbidity of the crystallization solution, thereby a considerable number of crystals have to be formed to detect a significant increase in the turbidity of the solution. For the highest sodium chloride concentrations, experiments were characterized by a strong nucleation giving rise to a high number of crystals in solution, and in turn an important increase in the turbidity of the solution. In contrast, lower sodium chloride concentration experiments did not lead to a noteworthy change in the turbidity of the solution, in particular when only tetragonal crystals were observed. For those cases, crystallization solutions kept relatively clear throughout the experiment despite the presence of crystals in solution. This partly explains the large variation in the induction time values (error bars), which can also be explained by the stochastic nature of nucleation and the low probability that nuclei form at low supersaturations. From Figure 8, one can verify that for the same sodium chloride concentrations $(4 \%(\mathrm{w} / \mathrm{v}))$ and lower $S_{\mathrm{i}}$ 
Table 2. Experimental Conditions for Lysozyme Crystallization As a Process Step in the meso-OFR at $20{ }^{\circ} \mathrm{C}$ and $\mathrm{pH} 4.7$ and under Agitation Conditions of $f=1.83 \mathrm{~Hz}$ and $x_{0}=4 \mathrm{~mm}$

\begin{tabular}{|c|c|c|c|c|c|c|c|}
\hline $\begin{array}{c}{[\mathrm{NaCl}]} \\
(\%(\mathrm{w} / \mathrm{v}))\end{array}$ & [Lysozyme] $\left(\mathrm{mg} \cdot \mathrm{mL}^{-1}\right)$ & $S_{\mathrm{i}}$ & typical crystal size $(\mu \mathrm{m})$ & crystal shape & $\begin{array}{l}\text { crystal yield } \\
(\%)\end{array}$ & $\begin{array}{l}\text { relative activity } \\
(\%)\end{array}$ & $t_{\text {ind }}(\min )$ \\
\hline 2.5 & 50 & 33.3 & $10 \pm 4.6$ & tetragonal & & \multirow{5}{*}{$>85$} & \\
\hline \multirow[t]{4}{*}{3} & 25 & 3.4 & $9.3 \pm 4.0$ & \multirow[t]{4}{*}{ tetragonal } & $47.5 \pm 11.9$ & & $528 \pm 239$ \\
\hline & 30 & 4.1 & $9.8 \pm 3.9$ & & $43.6 \pm 21.5$ & & $465 \pm 15$ \\
\hline & 35 & 4.8 & $8.4 \pm 3.4$ & & $36.2 \pm 22.7$ & & $735 \pm 135$ \\
\hline & 40 & 5.5 & $7.6 \pm 4.1$ & & $76.0 \pm 12.5$ & & $552 \pm 19$ \\
\hline \multirow[t]{4}{*}{4} & 15 & 5.4 & $6.5 \pm 2.9,10-50^{a}$ & \multirow{3}{*}{$\begin{array}{l}\text { tetragonal, orthorhombic, and } \\
\text { needle }\end{array}$} & 20.6 & \multirow[t]{4}{*}{$>80$} & $772 \pm 106$ \\
\hline & 20 & 7.1 & $13 \pm 8.8, \sim 20^{a}$ & & $40.1 \pm 12.9$ & & $338 \pm 60$ \\
\hline & 25 & 8.9 & $10 \pm 5.1, \sim 30^{a}$ & & $50.5 \pm 14.6$ & & 80 \\
\hline & 30 & 10.7 & $3.4 \pm 2.3$ & microcrystals & $52.1 \pm 47.5$ & & $41 \pm 1$ \\
\hline \multirow[t]{3}{*}{5} & 10 & 5.5 & $10-15$ & needle & $36.3 \pm 4.1$ & \multirow[t]{3}{*}{$>85$} & $917 \pm 34$ \\
\hline & 15 & 8.3 & $\sim 15$ & & $8.2 \pm 4.2$ & & 566 \\
\hline & 20 & 11.0 & & precipitate & $13.9 \pm 4.1$ & & $114 \pm 6$ \\
\hline 6 & 10 & 6.7 & $20-50$ & needle & & & \\
\hline
\end{tabular}

${ }^{a}$ These values correspond to the typical value of the length of the needles, their width being in the order of $1-2 \mu \mathrm{m}$.

values of $t_{\text {ind }}$ are shorter than the values reported in the literature. ${ }^{5}$ Indeed, Smejkal et al. ${ }^{5}$ related crystallization onsets from 350 to $570 \mathrm{~min}$ (stirrer speeds from 400 to $200 \mathrm{rpm}$, respectively) in a $6 \mathrm{~mL}$-scale stirred tank for $S_{\mathrm{i}}=9.7$, while we observed values of 80 and $338 \mathrm{~min}$ for $S_{\mathrm{i}}$ of 8.9 and 7.1, respectively. As already mentioned, the efficient oscillatory flow mixing mechanism developed in the meso-OFR leads to enhanced mass transfer, minimizing thus diffusion limitations that were reported to be the main bottleneck in the lysozyme crystallization process in nonagitated systems. ${ }^{5}$

Summary of Experimental Conditions. Table 2 summarizes the experimental crystallization conditions studied, as well as the respective crystals characteristics.

According to Table 2, criteria for protein crystallization as a process step were fulfilled, ${ }^{1}$ since well-defined lysozyme crystals with a typical size around $10 \mu \mathrm{m}$ were formed for low reagents concentrations. In addition, lysozyme crystals maintained their activity at the end of the process, since for most of the experimental conditions studied collected crystals exhibited at least $80 \%$ of activity. Further, crystallization process was relatively fast, since for certain operating conditions it was possible to detect the appearance of crystals after a few minutes. Regarding crystal yield, it was estimated using

$$
\operatorname{yield}(\%)=\frac{C_{\text {lysozyme intial }}-C_{\text {lysozyme final }}}{C_{\text {lysozyme initial }}} \times 100
$$

where $C_{\text {lysozymeinitial }}$ and $C_{\text {lysozymefinal }}$ are the initial and final lysozyme concentration estimated through UV absorbance $(\lambda=$ $280 \mathrm{~nm}$ ), respectively. In general the amount of crystals formed is low and further optimization is required, since yields of about $70 \%$ have been reported in the literature. For certain experimental conditions, it was not possible to evaluate precisely the size of the crystals, namely, when needles and precipitates were formed. Overlapping of the needles and small size and amorphous nature of precipitates prevented a proper assessment of their size.

\section{CONCLUSION}

The present work reports for the first time the study of lysozyme phase behavior in a novel meso oscillatory flow reactor (meso-OFR). For this, various experimental conditions were screened by varying lysozyme and sodium chloride concentration at $\mathrm{pH} 4.7$ and $T=20{ }^{\circ} \mathrm{C}$ and under fixed agitations conditions $\left(f=1.83 \mathrm{~Hz}\right.$ and $\left.x_{0}=4 \mathrm{~mm}\right)$. The results obtained enabled the elaboration of a two-dimensional lysozyme phase diagram (lysozyme concentration against sodium chloride concentration). It was possible to observe several types of crystals, from tetragonal, orthorhombic and needle-shaped crystals, to microcrystals and precipitates. Results further suggest a strong influence of salt concentration on the shape of lysozyme crystals. Furthermore, lysozyme crystals formed remain active at the end of the experiments. It was also shown that oscillatory flow mixing promotes nucleation at low supersaturation, since results evidenced the reduction of the metastable zone and short induction times.

This study may thus provide improved understanding of protein phase behavior under agitation, in particular under oscillatory flow mixing. Although further optimization is still required, especially regarding yield and control of crystals' characteristics (size and morphology), results are very promising regarding the applicability of the designed mesoOFR for protein crystallization as a process step. Indeed, oscillatory flow mixing can induce nucleation in conditions where nucleation normally (quiescent conditions) does not occur, which can be particularly interesting from an industrial point of view.

\section{AUTHOR INFORMATION}

\section{Corresponding Author}

*Tel.: +35122508 16 87. E-mail: filipaj@fe.up.pt.

\section{Notes}

The authors declare no competing financial interest.

\section{ACKNOWLEDGMENTS}

This work was financially supported by the European Regional Development Fund (FEDER) through COMPETE 2020Operational Programme Competitiveness and Internationalization (POCI) (UID/EQU/00511/2013-LEPABE-Laboratory for Process Engineering, Environment, Biotechnology and Energy-EQU/00511; POCI-01-0145-FEDER-006684) and by national funds through FCT-Portuguese Foundation for Science and Technology-under the projects: UID/BIO/ 04469/2013; IF exploratory project [IF/01087/2014]; postdoctoral Fellowship [SFRH/BPD/96132/2013]. A. Ferreira is an Investigator FCT (IF/01087/2014). 


\section{REFERENCES}

(1) Etzel, M. R. In Process Scale Bioseparations for the Biopharmaceutical Industry; Taylor \& Francis Group, LLC, 2007; pp 159-178.

(2) Lee, E. K.; Kim, W. Protein Crystallization for Large-Scale Bioseparation; Marcel Dekker, 2003.

(3) McPherson, A.; Gavira, J. a. Acta Crystallogr., Sect. F: Struct. Biol. Commun. 2014, 70, 2-20.

(4) Schmidt, S.; Havekost, D.; Kaiser, K.; Kauling, J.; Henzler, H.-J. Eng. Life Sci. 2005, 5, 273-276.

(5) Smejkal, B.; Helk, B.; Rondeau, J.-M.; Anton, S.; Wilke, A.; Scheyerer, P.; Fries, J.; Hekmat, D.; Weuster-Botz, D. Biotechnol. Bioeng. 2013, 110, 1956-1963.

(6) Thommes, J.; Etzel, M. Biotechnol. Prog. 2007, 23, 42-45.

(7) Neugebauer, P.; Khinast, J. G. Cryst. Growth Des. 2015, 15, $1089-1095$.

(8) Shenoy, B.; Wang, Y.; Shan, W.; Margolin, A. L. Biotechnol. Bioeng. 2001, 73, 358-369.

(9) Smejkal, B.; Agrawal, N. J.; Helk, B.; Schulz, H.; Giffard, M.; Mechelke, M.; Ortner, F.; Heckmeier, P.; Trout, B. L.; Hekmat, D. Biotechnol. Bioeng. 2013, 110, 2452-2461.

(10) Jacobsen, C.; Garside, J.; Hoare, M. Biotechnol. Bioeng. 1998, 57, 667-675.

(11) Huettmann, H.; Zich, S.; Berkemeyer, M.; Buchinger, W.; Jungbauer, A. Chem. Eng. Sci. 2015, 126, 341-348.

(12) Hekmat, D.; Hebel, D.; Schmid, H.; Weuster-Botz, D. Process Biochem. 2007, 42, 1649-1654.

(13) Anderson, M. J.; Hansen, C. L.; Quake, S. R. Proc. Natl. Acad. Sci. U. S. A. 2006, 103, 16746-16751.

(14) Asherie, N. Methods 2004, 34, 266-272.

(15) Hebel, D.; Huber, S.; Stanislawski, B.; Hekmat, D. J. Biotechnol. 2013, 166, 206-211.

(16) Parambil, J. V.; Schaepertoens, M.; Williams, D. R.; Heng, J. Y. Y. Cryst. Growth Des. 2011, 11, 4353-4359.

(17) Judge, R. A.; Johns, M. R.; White, E. T. Biotechnol. Bioeng. 1995, 48, 316-323.

(18) Yaoi, M.; Adachi, H.; Takano, K.; Matsumura, H.; Inoue, T.; Mori, Y.; Sasaki, T. Jpn. J. Appl. Phys. 2004, 43, 1318.

(19) Murai, R.; Yoshikawa, H. Y.; Kawahara, H.; Maki, S.; Sugiyama, S.; Kitatani, T.; Adachi, H.; Takano, K.; Matsumura, H.; Murakami, S.; Inoue, T.; Sasaki, T.; Mori, Y. J. Cryst. Growth 2008, 310, 2168-2172. (20) Lu, Q.-Q.; Yin, D. C.; Liu, Y. M.; Wang, X. K.; Yang, P. F.; Liu, Z. T.; Shang, P. J. Appl. Crystallogr. 2010, 43, 473-482.

(21) Vekilov, P. G.; Rosenberger, F. J. Cryst. Growth 1998, 186, 251261.

(22) Pusey, M.; Witherow, W.; Naumann, R. J. Cryst. Growth 1988, 90, 105-111.

(23) Harrison, R.; Todd, P.; Rudge, S.; Petrides, D. Bioseparation Science and Engineering; Oxford University Press: New York, 2015.

(24) Carbone, M. N.; Etzel, M. R. Biotechnol. Bioeng. 2006, 93, 12211224.

(25) Lorber, B.; Skouri, M.; Munch, J.-P.; Giegé, R. J. Cryst. Growth 1993, 128, 1203-1211.

(26) Judge, R. A.; Forsythe, E. L.; Pusey, M. L. Biotechnol. Bioeng. 1998, 59, 776-785.

(27) Takakura, T.; Ito, T.; Yagi, S.; Notsu, Y.; Itakura, T.; Nakamura, T.; Inagaki, K.; Esaki, N.; Hoffman, R. M.; Takimoto, A. Appl. Microbiol. Biotechnol. 2006, 70, 183-192.

(28) Lee, T.; Vaghjiani, J.; Lye, G.; Turner, M. Enzyme Microb. Technol. 2000, 26, 582-592.

(29) Giffard, M.; Ferté, N.; Ragot, F.; El Hajji, M.; Castro, B.; Bonneté, F. PLoS One 2011, 6, e19013.

(30) Zang, Y.; Kammerer, B.; Eisenkolb, M.; Lohr, K.; Kiefer, H. PLoS One 2011, 6, e25282.

(31) Trilisky, E.; Gillespie, R.; Osslund, T. D.; Vunnum, S. Biotechnol. Prog. 2011, 27, 1054-1067.

(32) Ferreira, A.; Rocha, F.; Teixeira, J. A.; Vicente, A. Apparatus for mixing improvement based on oscillatory flow reactors provided with smooth periodic constrictions. Int. Patent WO/2015/056156, 2014.
(33) Harvey, A.; Mackley, M. R.; Reis, N.; Teixeira, J. A.; Vicente, A. A. In Proceedings of the 30th Conference SSCHE, Tatranske Matliare (SK), 26-30 May 2003; pp 26-30.

(34) Ferreira, A.; Teixeira, J. A.; Rocha, F. Chem. Eng. J. 2015, 262, 499-508.

(35) Castro, F.; Ferreira, A.; Rocha, F.; Vicente, A.; Teixeira, J. A. AIChE J. 2013, 59, 4483-4493.

(36) Castro, F.; Ferreira, A.; Rocha, F.; Vicente, A.; Teixeira, J. A. Ind. Eng. Chem. Res. 2013, 52, 9816-9821.

(37) Jiang, S.; Ter Horst, J. H. Cryst. Growth Des. 2011, 11, 256-261.

(38) Di Profio, G.; Curcio, E.; Cassetta, A.; Lamba, D.; Drioli, E. J. Cryst. Growth 2003, 257, 359-369.

(39) Forsythe, E. L.; Judge, R. a.; Pusey, M. L. J. Chem. Eng. Data 1999, 44, 637-640.

(40) Martins, P. M.; Rocha, F.; Damas, A. M. PLoS One 2008, 3, e1998.

(41) Crespo, R.; Martins, P. M.; Gales, L.; Rocha, F.; Damas, A. M. J. Appl. Crystallogr. 2010, 43, 1419-1425.

(42) Bhamidi, V.; Skrzypczak-Jankun, E.; Schall, C. A. J. Cryst. Growth 2001, 232, 77-85.

(43) Tait, S.; White, E. T.; Litster, J. D. Cryst. Growth Des. 2009, 9, 2198-2206.

(44) McPherson, A. Crystallization of Biological Macromolecules; Cold Spring Harbor: New York, 1999.

(45) Kusters, K. A.; Wijers, J. G.; Thoenes, D. Chem. Eng. Sci. 1997, 52, 107-121.

(46) Thomas, C. R.; Geer, D. Biotechnol. Lett. 2011, 33, 443-456.

(47) Bee, J. S.; Stevenson, J. L.; Mehta, B.; Svitel, J.; Pollastrini, J.; Platz, R.; Freund, E.; Carpenter, J. F.; Randolph, T. W. Biotechnol. Bioeng. 2009, 103, 936-943.

(48) Sandwick, R. K.; Schray, K. J. J. Colloid Interface Sci. 1987, 115, $130-138$.

(49) Caussette, M.; Gaunand, A.; Planche, H.; Colombié, S.; Monsan, P.; Lindet, B. Enzyme Microb. Technol. 1999, 24, 412-418.

(50) Caussette, M.; Gaunand, A.; Planche, H.; Monsan, P.; Lindet, B. Ann. N. Y. Acad. Sci. 1998, 864, 228-233.

(51) Colombié, S.; Gaunand, A.; Lindet, B. Enzyme Microb. Technol. 2001, 28, 820-826.

(52) Postel, C.; Abillon, O.; Desbat, B. J. Colloid Interface Sci. 2003, 266, 74-81. 